\title{
Sport for Development and Peace in Divided Societies: Cooperating for Inter-Community Empowerment in Israel
}

\author{
Nico Schulenkorf ${ }^{1}$ and John Sugden ${ }^{2}$ \\ ${ }^{1}$ University of Technology Sydney, Australia \\ ${ }^{2}$ University of Brighton, UK
}

\begin{abstract}
The idea of using sport for social, cultural and community development has been promoted for decades; however, only limited empirical research can be found that analyses the strategic potential of sport projects in contributing to conflict resolution, reconciliation and peace building in deeply divided societies. This study concentrates upon the experiences of a number of Football for Peace (F4P) projects operating in Israel in 2009. It identifies and investigates the inter-community sport management strategies employed in a particular project that featured Jewish, Arab, and Circassian communities in Northern Israel. The article focuses on and assesses the role played by external change agents in facilitating project delivery and development. Following an interpretive mode of enquiry, observations and focus group discussions with key project facilitators and sport coaches were conducted exploring participant experiences and using this information to develop practical recommendations for social development through sport. The following six strategic dimensions were elicited as critical elements for promoting positive inter-community relations, building local capacity and enhancing overall social development: greater emphasis on training for all volunteers; the provision of role model support; the development of local commitment and leadership; improvement of sport programming; the facilitation of wider community involvement; and project augmentation and extension. We argue that these practical suggestions have transferable implications for other grassroots organisations and NGOs that use sport projects in divided and/or disadvantaged communities elsewhere in the world.
\end{abstract}

Keywords: Sport-for-Development, Sport Management, Change Agents, Community Relations, Sport Leverage, Qualitative Research

\section{Introduction}

Within the areas of sport management and sport sociology, the sport-for-development phenomenon has been advanced as an active, inclusive and exciting vehicle for (inter-)community wellbeing along a number of dimensions. For example, different sport programs have been conducted to create social capital and social change within and between communities (Kay, 2009; Skinner, Zakus \& Cowell, 2008); to positively alter gender roles and increase female participation in sport (Meier \& Saavedra, 2009); and to support trauma-relief efforts as a post-disaster intervention in disad- 
vantaged communities (Gschwend \& Selvaranju, 2007; Kunz, 2009). In culturally or ethnically divided societies, international aid organisations, NGOs and grassroots initiatives have further engaged in sport and event projects to assist disparate groups in establishing contact, reducing and resolving conflict, and building inter-community bridges (Gasser \& Levinsen, 2004; Schulenkorf, 2010b; Sugden, 2006).

Since 2001, the 'Football for Peace' (F4P) initiative has been conducting sportfor-development projects in the ethnically divided Galilee region of Northern Israel. Since its inception F4P has generated a wealth of evaluative material, some of which has been used to inform a variety of publications ranging from the descriptive (Whitfield, 2006) the interpretive (Sugden \& Wallis, 2007) and the analytical/theoretical (Sugden \& Haasner, 2010). This paper adds to this body of knowledge by empirically examining the organisation and implementation phases of one particular F4P project. In doing so, it responds to the claim for 'harder management evidence' (Spaaij, 2009) by investigating how inter-community development through sport actually works.

\section{Sport-for-Development Programs}

This paper is concerned with one particular dimension of the sport-for-development phenomenon: the use of sport in the service of conflict resolution, peaceful co-existence and reconciliation in deeply divided societies (Gasser \& Levinsen, 2004; Levermore \& Beacom, 2009; Sugden \& Wallis, 2007). For a long time, empirical evidence for positive social outcomes from sport and event projects has been difficult to find (Coalter, 2010). However, recently some empirical studies have presented limited evidence that sport-for-development initiatives can indeed encourage healthy competition, promote friendship and develop intergroup understanding, resulting at times in long-term social, cultural and psychological development (Gasser \& Levinsen, 2004; Schulenkorf, 2010b; Stidder \& Haasner, 2007; Sugden, 2006). From a theoretical perspective, Misener and Mason (2006) expected that people who participate in sportive or cultural expression could be empowered through being creative, developing and using skills, and contributing to inclusive social identities. Confirming this claim empirically, Kay (2009) in her study on young women and adult sport workers in Delhi, India, found that sport can be an agent of personal and social change. Kay argued that sport can provide people from disadvantaged groups with increased selfconfidence, which was derived from increased body confidence or the ability to be a team-player and leader during sport activities. Similarly, Skinner, Zakus and Cowell (2008) suggested that as a result of team sport activities a broad array of positive social outcomes such as personal and community networks can be developed, which have the ability to result in high levels of inclusive social capital for disadvantaged communities.

Sport projects have also been purposely implemented as trauma-relief instruments. In 2007, the Swiss Academy for Development (SAD) reviewed the programs 
of different grassroots organisations around the world that used psychological sport programs as a tool for overcoming trauma in post-disaster environments. Findings suggested that sport projects - if managed strategically and under supervision of professionally trained staff - can be expected to be effective vehicles for trauma-relief and inclusion among populations affected by disasters, civil unrest or war (Gschwend \& Selvaranju, 2007). More recently, an empirical study on sport and play conducted by Kunz (2009) in Bam, Iran, confirmed that sport is able to contribute to psychological rehabilitation and post-disaster relief for children who suffered the consequences of a devastating earthquake. Importantly, the sport coaches of the project - who acted as supervisors and facilitators between individuals and groups - played a crucial role in the psychological rehabilitation efforts of traumatised children and the building of mental and social capacities.

Overall, it has been argued that social development contains three main interrelated constructs: social capital; social change; and capacity building (Moscardo, 2007). While social capital refers to the development of trust, networks and reciprocity among people, social change refers to the establishment of emotional connections and bonds among communities, such as the creation of a common social identity and a sense of belonging. Capacity building describes the enhancement of material opportunities or particular skills, talent, attitudes and knowledge that contribute to community empowerment. In order to build capacities within and between communities, it is necessary for all participating groups - communities, project organisers and external stakeholders alike - to actively engage and cooperate (Lawson, 2005). Particularly in divided societies, inter-community cooperation and a commitment for a peaceful togetherness are the pre-conditions for any type of social development. Building on Christenson, Fendley and Robinson's (1989: 14) definition of community development, inter-community development can thus be described as "different groups of people initiating a social action process (i.e. an intervention) to improve their overall economic, social, cultural, or environmental situation". From a social perspective, inter-community development should therefore be understood as an ongoing process, in which commitment, active participation and cooperation between all groups are the preconditions for creating positive social experiences and achieving lasting social outcomes.

In order to avoid the problems of overwhelming communities with the staging of development projects, several authors highlight the importance of establishing creative and cooperative partnerships with external institutions or 'change agents' which are able to guide and support the process (Lawson, 2005; Naparstek, Dooley \& Smith, 1997). In cases where international change agents are involved in inter-community development process, they are required to respect local traditions and avoid paternalistic behaviour in an attempt to share control and power with local communities (Schulenkorf, 2010a; Skinner et al., 2008). In fact, change agents should be serv- 
ing as a supportive enabler and facilitator for projects and networks of partnerships between residents, management, and community organisations (Ife, 1995; Kramer $\&$ Specht, 1975). They are expected to foster grass-roots participation and integrate people and communities from different backgrounds, so that they engage in common tasks and seek common goals. As a supporting contact, change agents have to try and foster collective solidarity by respecting and using the individual characteristics of each community in a way that every group is satisfied (Lawson, 2005; Midgley, 1986; Uruena, 2004). Finally, change agents are supposed to merely guide communities to use their capacities effectively, rather than dictating 'the way to go'. Darnell (2007) supports this argument highlighting that change agents from the Global North - who are working at sport development projects with all good intentions - may be equipped with knowledge of sport but no knowledge of local cultures, traditions and customs in the Global South. Ideally their external technical knowledge is combined with local skills and input, which leads to reciprocal learning and all stakeholders benefiting from newly acquired methods and activities. This paper uses a particular inter-community project of the 2009 Football for Peace (F4P) initiative in Israel adding to much needed empirical evidence in this field.

\section{Football for Peace}

In summary, Football for Peace (F4P) can be described as a grassroots sport based co-existence project that focuses on improving intergroup relations between disparate communities in societies in conflict. In 2001 - operating under the label of WSP (World Sport Peace Project) - six volunteer coaches from the University of Brighton and one staff leader conducted the first F4P project week in Northern Israel (Whitfield, 2006). They engaged in a seven days coaching camp in the Arab town of Ibillin and provided football sessions for approximately 100 Muslim Arab and Christian Arab children (10-14 years old). The intention had been to involve the nearby Jewish community of Misgav. However, the planing phase for this first intervention coincided with the start of the second intafada or 'uprising' which saw violent confrontations spread from Palestine's West Bank into Israel, including towns and cities in Galilee. Under these circumstances Misgav withdrew its initial commitment, but did return to the programme a year later along with the neighbouring Jewish community of Tivon. Today the cross community partnership between Ibillin and Misgav is stronger than ever and represents the exemplary bedrock of Football for Peace.

Within nine years of operation, F4P grew to encompass 13 individual projects, or Cross Community Sport Partnerships (CCSPs) with 33 participating communities, mainly in the Galilee region. Today F4P is supported not only by the University of Brighton, but also through partnerships with the British Council Israel, the Israeli Sports Administration, the German Sports University in Cologne, Cologne City Council, the (English) FA, the German FA, and hundreds of voluntary co-workers 
and volunteers. In terms of the latter, as active change agents their overall goal is to contribute to peace and reconciliation through sport, and to support local Jewish, Arab and Circassian communities in transcending their social, cultural, ethnic, and religious divides.

F4P projects are presented as taking place in neutral, politics-free zones, and all project participants - players, coaches, parents, administrators - are asked to leave their political views and ideological positions outside the project zones. Within this relatively safe space participants engage in a variety of sporting and cross-cultural activities. F4P offers an evolving, values-based educational curriculum centred on the five key principles of inclusiveness, equality, respect, trust, and responsibility which all feed into the ways through which the projects are structured and delivered. This delivery is led by overseas volunteers in collaboration with local volunteers who have all experienced a period of F4P volunteer training on a European university campus.

While each project will have certain nuanced differences determined by prevailing local circumstances there is a basic pattern and structure which all F4P programmes follow. Each project recruits one hundred children divided in two age groups $(8-10 ; 11-13)$ At the beginning of each project the age-groups are further divided in four coaching sets which are a mixture of Jewish and Arab players (50:50). Each coaching set is facilitated by an overseas volunteer coach supported by two local coaches, one Arab and the other Jewish. During the next five days the coaching sets engage with the F4P values-based coaching curriculum that is laid out in three languages (Hebrew, Arabic and English) in the F4P coaching manual. During this time the coaching sets grow into teams which come together at the end of the programme to participate in an expansive F4P Festival of Football ${ }^{1}$.

\section{Socio-Cultural Context and Rationale}

The shape and structure of F4P has not evolved in a vacuum. Those wishing to use sport to assist with the achievement of broader development goals need to carefully study and understand the nature of the cultural setting in which they choose to operate. However, for the purpose of this paper only a brief outline of the key sociopolitical and demographic features that are the most pertinent to F4P can be outlined.

The state of Israel was controversially created in 1948 in the long shadow of World War Two. While this can be seen as a major achievement for the hitherto nation-less and persecuted Jewish people, in equal measure it can be viewed as a disaster for the Palestinians on whose land the fledging state took shape. In 1948 only 160,000 Arabs stayed in Israel, the rest, some 640,000 fled, mainly to neighbouring Jordan,

$1 \quad$ Full details concerning the methodology of F4P can be found in the book, Football for Peace? The Challenges of Using Sport for Co-Existence in Israel (Sugden \& Wallis, 2007), and the theoretical model that underpins it is explored in the journal article, Critical left realism and sport interventions in divided societies (Sugden, 2010). 
Syria and Lebanon (today the Palestinian Diaspora number approx. 3.5 million in the region). Approximately 2.5 million Palestinians live in the Occupied Territories (West Bank and Gaza), some of the most densely populated places on earth. Perhaps rightly so, the situation of the Palestinians within the Occupied Territories, the plight of the Palestinian diaspora, and the Israeli State's engagement with these external factors attract most global attention. However, often forgotten by the international community, and the main concern of this paper, is the status of relations between the various constituencies who remained within the state of Israel after 1948.

By the year 2000, Jewish Israelis numbered approximately 5.5 million, made up of a mixture migrant first generation European and Americans, Ethiopian Jews (Falash Mura), and more recent arrivals from the former Soviet Union and other Eastern Bloc countries. While in terms of religious persuasion the majority of the Jewish population consider themselves to be secular, a significant minority are devoted adherents to the Hebrew faith. This religious orthodoxy is a key dimension of Israel's fractured political make-up. The number of 'Palestinian-Arab-Israeli' citizens is approximately 1.2 million, roughly $18 \%$ of the population. This too is an exceedingly complex identity. The order of its wording changes depending upon the political consciousness of the individual bearing it. It is further complicated via the religious and ethnic suffixes that can be added: Moslem (Sunni and Shiite); Christian; Druze; and so forth, not to mention different tribal/ethnic affiliations, such as the Bedouin and Circassians which also inform the mapping of the county's sectarian geography.

Against this complex background, the late and highly respected Palestinian academic and activist, Edward Said believed that co-existence, not separation, is the way forward if a lasting peace is to be achieved in Israel. He pointed out, "we cannot coexist as two communities of detached and uncommunicatingly separate suffering... the only way of rising beyond the endless back-and-forth violence and dehumanisation is to admit the universality and integrity of the other's experience and to begin to plan a common life together" (Said, 2002, 208). Likewise, Naim Ateek, a senior Christian-Arab cleric, argues that any lasting peace in the region must be based upon reconciliation which itself is dependent upon mutual recognition of and respect for different cultural traditions and the history of oppression and suffering that underpins those traditions. "Before the process of peacemaking can begin, a change in attitude of Israeli Jews and Palestinians towards one another is necessary. They need to face each other with candour, to create the new attitudes that will be the foundation for peace and stability in the region" (Ateek, 1989, 168). These arguments are fundamental in providing a rationale for projects like F4P.

\section{The 2009 Kfar Kama Project}

Circassians present a minority in Israel, who emigrated from the south of Russia in the late $19^{\text {th }}$ century to avoid genocide in their traditional Caucasus homeland. They 
are well known for adapting to prevailing social and cultural conditions including taking on the dominant religion of the regions in which they have settled. In the nineteenth century Islam was the dominant religion of the Ottoman Empire which ruled over the Land now known as Israel, and this was the faith adopted by the Circassians even though they are not Arabs (Allen \& Muratoff, 1953). In Israel, Circassians have maintained a largely neutral stance in relation to the conflicts between their Arab and Jewish neighbours. In addition to their native Adyghe language Circassians learn English, Hebrew and Arabic at school, which makes them ideal communicators between the diverse Israeli communities.

Kfar Kama is one of only two Circassian villages in Israel, which is nestled in the shadow of Mount Tabor, between the Jewish town of Kfar Tavor and the Arab community of Buena Nujeidat. In June 2009 Kfar Kama hosted one F4P project and provided the basis for the following case study. The project included a mixture of 100 children (aged 10-14 years old) from the neighbouring communities of Kfar Kama (Circassian), Lower Galilee (Jewish) and Buena Nujeidat (Arab), who came together for a week of inter-cultural 'on-pitch' and 'off-pitch' activities. On-pitch activities refer to the actual football training sessions and games, whereas off-pitch activities describe the engagement in leisure-based team building activities. Every day, ethnically mixed groups of children spent $50 \%$ of their time on the football field, playing with each other and learning new technical skills through the values-based F4P football methodology. The other half of the day they engaged in social inter-community development activities such as trust games, orienteering sessions, cultural performances and outdoor adventure games.

The Kfar Kama project was facilitated by five international volunteer sport coaches from Brighton University and Cologne Sports University, who acted as change agents (see Schulenkorf, 2010a) between the participating community groups. As change agents, the international volunteers did not only attempt to improve the children's football skills, but they also focused on overcoming intergroup rivalry and reducing ethnic distance between the respective parties. Indeed, the change agents aimed to promote intimate interaction between the children and their communities, allowing for the establishment of longer-term relationships and cross-community understanding.

Before the project in May 2009, the volunteer coaches had attended a training workshop in Germany, where they were introduced to the distinctive F4P program. Furthermore, they got the chance to get to know each other and to meet and train alongside representatives from the diverse communities in Israel. During the weeklong Kfar Kama project implementation phase, the international group was mainly in charge of the football sessions, while regional sport managers and local volunteers from all three communities were responsible for providing facilities and equipment 
and organising the off-pitch activities, as well as providing coaching support and much needed translation services.

\section{Method}

This study empirically examined the organisation and implementation phases of the 2009 Kfar Kama F4P project. In particular, it attempted to identify and investigate the inter-community sport management strategies employed in the project and then use this information to develop practical recommendations for social development through sport. The interpretive paradigm that underpins this study acknowledges that research questions, themes and data emerge through a process of induction (Crotty, 1998; Glesne, 1999; Neuman, 2003). That is, the researchers aim to understand the context of a phenomenon through the meanings that people assign to it (Myers, 1997). In other words, they construct and reconstruct meaning in relation to the evolving research questions and findings, i.e. the experiences of the participants related to the phenomenon under inquiry (Denzin \& Lincoln, 2005).

Findings from this research were derived by conducting observational research and six semi-structured focus group discussions with the five international volunteer sports coaches. Every night during the Kfar Kama sport project in June 2009, respondents talked and reflected critically on their management and social experiences of the day. For example, they reported on their impressions of the project management; the importance, challenges and level of local community involvement in staging the projects; and the social, cultural and psychological impacts and development witnessed. Finally, based on their impressions and experiences potential strategies for programme improvement were discussed.

The daily focus group sessions ran for between 35 and 80 minutes and were conducted by an independent researcher on site. The transcribed discussions along with observational field notes were used to build an extensive data base out of which grounded empirical and theoretical insights were garnered. The qualitative interrogation of the data was supported by the NVivo 8 software package, which assisted the researchers in storing, integrating, indexing, and coding the large amount of data collected.

The analysis process followed the descriptive, interpretive and pattern coding as set out by Miles and Huberman (1994). To identify emerging and reoccurring themes an initial broad (i.e. open) coding of all themes relevant to sport and community development was carried out by reading through each textual source. An important factor was the open-mindedness of the researchers and the re-testing of initial interpretations (Stake, 1995). The passages coded were then analysed and condensed into dominant themes or patterns deemed to be of central importance to the Kfar Kama project and future F4P initiatives. Finally, all of the themes were checked between coauthors for reliability (see Miles and Huberman, 1994). The five evaluative themes 
identified in relation to (inter-)community development through sport are: issues related to the training of local trainers; the value of local role modelling and leadership; matters around structure and programming; the involvement of the wider community; and project development and extension. All five evaluative themes will now be explored in detail from the perspectives of the international volunteers.

\section{Findings}

\section{Training}

The international volunteer sport coaches reported experiencing problems with local support staff members who had not been sufficiently trained in the F4P method, but who were nevertheless put in charge of some of the football and team-building sessions. They complained that such ad hoc staffing arrangements did not provide an environment conducive to social development through sport. It was observed that some of the locals had either not experienced one of the F4P training camps or if they had, they had not bought into the underpinning values. As one volunteer explained:

Some local coaches were only involved because they needed another person to manage a team. Ariel and another person from the community were brilliant football coaches but they did not understand the purpose of F4P, the values of trust, responsibility etc. So all they wanted to do was play football. They were even telling the children to move the cones closer together to make the goal smaller, so that it was harder for the opposite team to score. So they were basically telling their team to cheat. (FG: 101-103 / 976-982)

The comment highlights that some communities did not have enough official sport coaches available to support the project, and that some of the local amateur volunteer coaches were simply not prepared for their task. The Kfar Kama project leader remembered:

[The locals] were doing everything contrary to our teaching... For example, they were doing things like tug-of-war today, which in my opinion goes against what we were trying to get out of the kids. The way it was set up... there was a clear division between winners and losers. So there was again that competition element that we did not want to emphasise... (FG: 378-387)

In order to prevent these issues from happening in the future, the interviewees recommended the strategic inclusion of compulsory cascade training sessions during the pre-project stage. At the 2009 pre-event workshop in Cologne, it was mainly the Israeli community leaders and official representatives who were present, not the actual sport coaches. The interviewees suggested a change of focus towards "the people who are actually running the sessions, rather than the 'bosses'. [That] would 
be helpful to get the values of F4P across" (FG: 359-362). Building on this argument, another volunteer stressed the importance of educating local coaches for reasons of project continuity and overall sustainability, suggesting that "obviously after we (the internationals) go, these guys are going to be the ones carrying on to coach football throughout the year" (FG: 367-369).

A further suggestion was made by an English coach, who recommended a separate training workshop to be staged on site in Israel, which could include and prepare the entire group of local community coaches. He argued:

You could always try and get eight English coaches to Israel and... they could train the trainers here... Everybody who is taking part in the project should be there. If you're not attending [the training camp], you are not taking a coaching role at the project. So that way you could brief people and get their confidence up, so that they understand the purpose of the on- and off-pitch activities. And that way people would meet each other beforehand - that would benefit the way things are run. (FG: 635-642)

Overall, a strategic change from 'informing the community leaders' towards 'training the trainers' was expected to have long-term benefits, as local coaches would be empowered through additional technical know-how and further understanding of socio-cultural teaching methods. A volunteer summed up:

This means that [in the long run] you would not have to explain all drills to the locals, as they would already have the experience. So when the football side is tight, they can then focus more on the social aspects. So if they were taught the drills before at the training camp and they have the manuals etc., you can then focus more on specifics such as when to point the 'teachable moments' out, when to focus on social issues etc. (FG: 644-649)

\section{Role Models and Leadership}

Many interviewees reported on the importance of having community-based role models who support the children during their sport and social activities. Particularly in the cultural off-pitch sessions, role models were identified as the key to social engagement, participation and development:

There was no Jewish role model involved in the dancing. The cultural off-pitch activities were pretty much run by the Arabs and Circassians only, and there was no Jewish representative leading something or doing something, which would have been important for the Jewish kids. Say, if you are a Jewish kid and you watch people that have nothing to do with you, and your leaders are not there, you just switch off. (FG: 134-138) 
Role model support was considered important from both a moral and integrative perspective, particularly in situations where cultural differences are strongly observable. One volunteer explained that despite efforts from the international coaches, the Jewish children "were reluctant to join the others and dance. Even if they got up for a minute, their friends were not there and so they sat down again. It was hard without Jewish coaches or role-model support" (FG: 233-236).

In other examples, Arab and Circassian community leaders presented great role models and encouraged the children to (literally) join hands with others. They assisted in building social bridges and it became obvious that in many instances their behaviour was mirrored by the youngsters. Unfortunately, it was not only positive behaviour that had an impact on the children, as one international coach explained:

If the coaches start arguing like they did a couple of times yesterday, everything that you have done is just lost... The kids start to leave the group circle wanting to join them, they were looking into their direction and it was hard to connect and talk with them. The adults are role models and if they don't behave, the whole week's work is just lost. (FG: 835-838 / 995-997)

According to the interviewees, a pre-requisite for success in inter-community development is the commitment and leadership of dedicated individuals who "make things happen' by providing a sport framework conducive to social development. For example, dedicated leaders organise the necessary equipment and 'go the extra mile' to allow projects to prosper. The Kfar Kama project coordinator Murad was identified by many of the international coaches as the prototype of a committed leader who was able to make a real difference:

Yesterday Felix had asked Murad if we could have more equipment for the separate stations. We got there today and we normally only needed two bags of balls, some bibs and cones, but today he had organised four bags of balls, four bags of bibs and four sets of cones. He was insisting of keeping them together, so I guess he must have borrowed them from somewhere else. But he got the stuff and we had an amazing amount of equipment, which allowed us to run the drills quicker and smoother. (FG: 718-724)

Whenever the international coaches asked for support or extra material, Murad found a way to organise additional equipment or people. Another example highlights the importance of his involvement as a community leader:

We asked Murad on Monday if he could organise materials to paint flags for the teams. He hadn't thought of this before, so we just asked him and he agreed. Within 24 hours we got the papers and he already got the paint etc. So the leader of the project was very committed and keen and he was able to find ways 
and organise everything we were asking. I think he is amazing: he's running around, always observing things, trying to help and improve and manage as well as he can. (FG: 726-734)

The importance of commitment and leadership becomes clear when looking at those instances where cooperation and dedication was lacking. If commitment is not there, things can go wrong and any type of social development may be undermined, as two international coaches explained:

While we were both energised to do things, trying to work things out, the local translators were sitting around the edge; they were on the phones and playing between themselves. Sometimes they even left and we asked 'What you are doing?'. We did not get any answer and felt a bit lost. (FG: 505-508)

On the pitch it could be observed that those local translators and support staff, who engaged enthusiastically with the children during activities, were able to achieve their social and educational goals more efficiently. One of the international volunteers pointed out the difference in two local translators who showed a varying degree of passion towards the $\mathrm{F} 4 \mathrm{P}$ project and its goals:

Kfir came to help and... I did not feel as if he was translating my words with the emphasis that he should. When Mashour came to help in between, the kids seemed to pick up a lot more information. So it is important to communicate the values and examples with energy and enthusiasm. (FG: 94-99)

The volunteer further explained that he could observe a change in the locals' confidence levels at the project. Especially the enthusiastic and committed local volunteers felt more self-assured and 'ready to go' once they had gained a clearer understanding of the sport-for-development concepts and practices. This development was believed to have resulted in increased satisfaction and individual empowerment:

Today Mahmood's brother was a lot more confident and enthusiastic. I had problems with him on days one and two, but this time, he had the experience with the specific drill. [Today] he knew what he was doing and I think this brought about even more enthusiasm... Now that he fully understood the drill and knew what it was all about, he was happy and ready to celebrate, pointing out 'teachable moments' etc. (FG: 618-625)

In addition to those people that were actively involved in the sport activities, the coaches highlighted that enthusiasm and commitment are qualities also needed from people around the peace project. They pointed out that at times they missed commitment and responsibility from the parents, which resulted in decreasing numbers of children participating in the daily F4P activities: 
The children are coming and going and the numbers seem to vary every day. For example, at the pool we had lots of kids missing... Overall, I started with 21 on day 1 and today I was down to 14 , so it gets less and less. F4P needs to somehow be more structured and organised that the kids who sign up for the project, that they are here for the 4-5 days constantly. Not that it turns into a voluntary come-and-go and parents think they can send the kids one day, miss out on another, but be back for the final festival. (FG: 658-669)

Interestingly, some interviewees mentioned that in cases where there were no adult role models available, some of the children stepped in and took the role of 'quasi role models' for their peers:

One thing that impressed me was one kid who translated everything for me and got many others involved, so there were small leaders among the kids who I pointed out as role models later to everyone. And once the kids realised they get the praise for their behaviour, they continued with it. So this boy helped me as a role model to get the values across. (FG: 558-562)

This offers a very good example of responsibility, one of the project's key underpinning values, in action.

\section{Structure and Programming}

During the week-long training sessions, local and international coaches tried to find the best structure and style to control and educate children on the one hand, and to keep them entertained and excited on the other. From an operational perspective, it took the coaches some time until they had identified the best set-up to achieve both these goals. While on days one and two the international coaches were responsible for all individual on-pitch activities and football games, on day three operational structures were changed and more responsibility was transferred to the local coaches:

It seemed to be a good idea to divide the field into different stations and have one of the Israeli translators responsible per station. So with your kids you walk around the stations and each time there is an Israeli coach who can explain the game on their own... If things went wrong, you could stop the game and interfere and explain things again, but that was not even needed. It was a good learning process for the translators/coaches, too. It increased their responsibility in running the games and their ability to do it properly. (FG: 572-580)

The increase in responsibility for the local translators - acting as support coaches had positive impacts on their self-assurance and levels of confidence. Respondents 
praised this outcome and commended the locals for their willingness and commitment to learning:

Today, the on-pitch was just brilliant. The structured circle set-up worked really well and everyone knew what they were doing. It gave the translators a lot more onus, because they stayed at their station and were able to explain the drill and values to the kids who came along. So they knew what values that drill was focusing on and we were able to run things a lot better and quicker and I believe the kids enjoyed it a lot more, too. So it went really, really well.

Overall, it was argued that this change in programming made the activities and changeovers "a lot smoother, just because you had that structure, you had those four stations. The kids knew exactly where they would go... and it was easy... They didn't even have a chance to misbehave" (FG: 585-588).

\section{Wider Community Involvement and Ownership}

The international coaches recommended an extension of the educational and social foci of F4P beyond the practical work with children alone. This suggestion builds on the experiences made at this year's project, where there was insufficient information provided to parents, friends and families who were therefore unable to engage and prepare children for the F4P project activities:

It would probably be a good idea to get the parents briefed on what F4P is about [because] I often think the kids don't know about F4P properly. They come here and think it is a football camp, and then they realise that it is not. Like it says, it is football for peace and it is more than football, it has a different focus. (FG: 684-686)

In particular the Jewish groups from the Lower Galilee region seemed ill-informed about the social purpose of F4P. In contrast, Arab supervisor Mashour had told the parents of the Buena Nujeidat community in advance about what F4P stands for and what it wants to achieve. According to the interviewees, this proactive and inclusive approach made a big difference to the success of the project:

Mashour got the phone numbers of all children from his Buena Nujeidat community to explain the project to all parents. Apparently there are a lot of projects out here like summer camps and other football projects ... So Mashour called all the parents and explained to them in a short phone call the values of the project. $\mathrm{He}$ argues that this often makes a difference and that families therefore decide to come to F4P. (FG: 688-695)

Considering the delicate political situation in Israel, personal contact was considered important to building trustful relationships between the community supervisor, the 
parents and their children. Personal conversations about the purpose and social value of F4P may have been the key to convincing parents to send their children to the project. However, while Mashour was successful in recruiting a large number of children, he was not able to convince a lot of parents to contribute and become actively involved in the F4P program. One international volunteer remembered:

I did not see a lot of parents... except the lady who said 'Thank you' at the end. The kids were all brought down by the community leaders. Maybe that's an organisational thing for the future, to get the parents to bring their kids and stay around... (FG: 280282)

Active involvement of parents and supporting families is something the international coaches would like to see, as the F4P idea could be expanded and leveraged to the wider community. They suggest to get the parents "to come to a few of the training days, just to see how we get the values across, that would help to understand the end result and grow the project further" (FG: 312-314). Indeed, one of the other 2009 F4P inter-community projects in the Upper Galilee region had already managed to include parents into the official program, providing them with a chance to become part of the F4P-family:

When I was speaking to Yossi in Upper Galilee yesterday, he was saying that on the final day before the festival the parents from both his partner-communities are invited to come and see the final training. Also, they are required to bring fruits and some of the drinks to contribute to the success of the day. (FG: 697-700)

\section{Growth and Development}

The international coaches believed that growing and leveraging the project is a promising step towards overall inter-community development. For the future, they suggest activities such as 'Dads-and-Lads Games' or 'mixed community partnership activities' which would help facilitate intergroup contact between children and parents from the Kfar Kama, Lower Galilee and Buena Nujeidat communities (FG: 710-712). One international volunteer summed up:

I think this is a great idea. Getting the parents to do exactly what the kids are doing, just in a slightly different way, is great. They would come, join and mix, which is good. You get them involved and they know what's going on. Also, for the kids it's important, as they want to shine and play and behave well in front of them (FG: 703-708).

Despite the overall support for the inclusion of parents into the program, one volunteer remarked that parents could also be a potential problem-factor for the overall success of the project. Clearly, the young man's comment needs to be taken into account when planning for future events: 
I could see the parents' presence as more of a problem than actual help. Just the fact that they have the wrong pre-conceptions before the project... So it might be an advantage to get the kids away from the parents, just so you don't have that negative influence... I mean, it clearly depends on what kind of parent it is, some might be very helpful, while others may be discouraging. It could be either way...

\section{Discussion and Conclusion}

Using Israel as an example for intergroup tensions and conflict, the aim of this research was to investigate the management and implementation strategies employed and/or recommended for the successful delivery of inter-community sport projects in divided societies. Five broad themes emerged from the examination of the $2009 \mathrm{Kfar}$ Kama Football for Peace (F4P) project, which was jointly staged by a Jewish, an Arabic and a Circassian community. The following section will discuss the five themes in relation to theory and previous studies in the area, and it will analyse in detail the opportunities and limitations in developing relationships through inter-community sport-for-development initiatives.

A focus on advancing local capacities through cascade training sessions was suggested to create an environment conducive to overall social development. It was argued that local volunteers need to be briefed and strategically prepared for the sport projects, so that they can fulfil their roles as supporting change agents (see Schulenkorf, 2010a). Ideally, this process should not be implemented ad hoc, but during the pre-project phase. An ex ante approach to social development should provide locals with a first insight into event planning and inter-cultural management, and with an opportunity to learn from management experts. For example, pre-project community workshops and cooperative coaching sessions under a 'train the trainers' approach could be conducted to transfer valuable management skills, technical knowledge and overall control to community members. This idea concurs with Burnett's (2001, 2006) experiences from sport-for-development projects in South Africa, where international change agents trained local coaches to train others as part of a 'training network'. Such a network is likely to combine external and internal experiences, strategies and content to meaningfully address the sport, social and cultural needs of the local communities. Importantly, the international sport coaches need to be willing to transfer responsibilities to the locals facilitating a 'bottom-up' management approach (Moscardo, 2007; Murphy, 1988). In their attempts to empower communities, they could follow the philosophical principles of Schulenkorf's (2010a) 'Model for Community Empowerment', which focuses on gradually reducing external dominance and increasing local control over time (see Figure 1 below). 
When staging inter-community projects in disadvantaged communities, the commitment and leadership of key individuals is a crucial factor for achieving positive social development. Going beyond Kay's (2009) and Meier and Saavedra's (2009) argument that sport can be an agent of personal change and development, this research shows that not sport per se, but the active involvement of passionate community leaders and change agents makes a strong contribution to positive intergroup development, cooperation and inclusive change. This implies that the conditions (e.g. downplay of competition and the focus on social values) and context of the event (e.g. combination of foreign experts and community support) are important success factors, particularly in a tension-laden environment. In this specific case, the inclusion of the Circassian community - who provided its sports ground as a neutral space for participation between Jewish, Arab, Circassian and international sportspeople may have further contributed to a positive and fruitful inter-community setting.

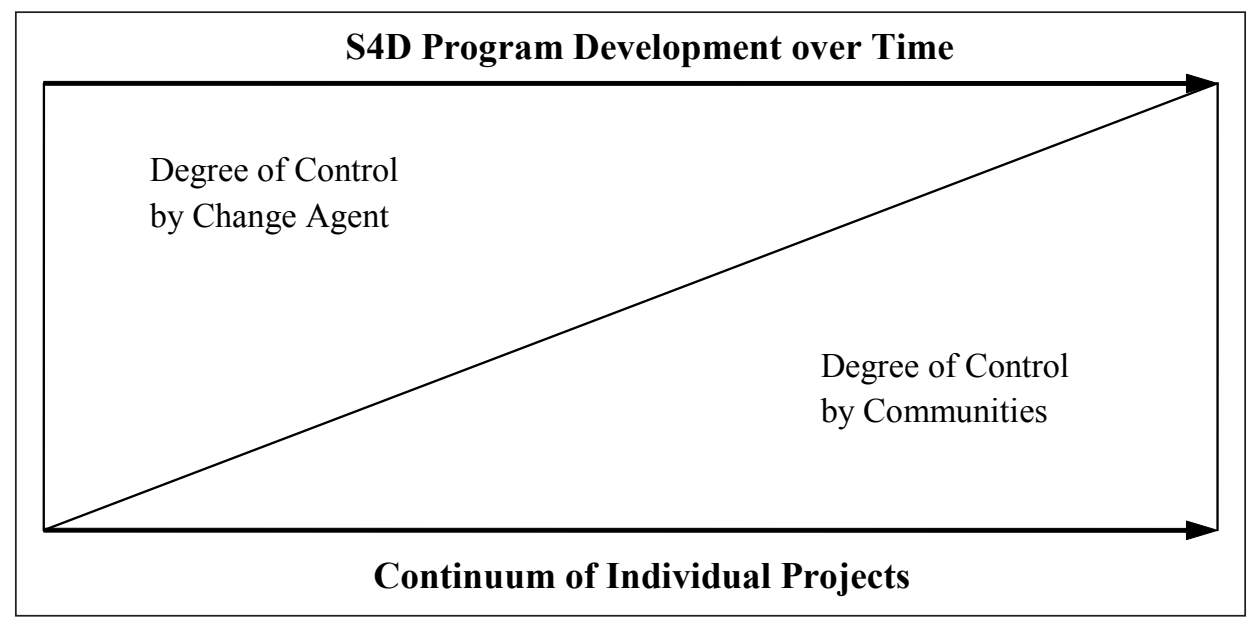

Figure 1: Schulenkorf's (2010) model of community empowerment

Next, local community members and role models should have a responsibility in the operational management of sport-for-development projects. While previous studies have highlighted the importance of key individuals sharing their knowledge and experiences to excite youth about professional/elite sport development (see e.g. Green \& Houlihan, 2005) this study shows that in a challenging multi-cultural environment adequate role model support is needed to encourage children to even participate in any type of interactive activity. For example, at the Kfar Kama project, the sociocultural off-pitch activities provided a challenge for children without their community leaders. It seems fundamentally important for peace projects to involve key individuals as role models, or - otherwise - build on self-confident children to take up this role instead. For project organisers and development coaches, the alternative of empowering children to become role models for their peers is an interesting direction 
to consider. However, further empirical work needs to be conducted to investigate the potential of local youth in supporting projects, in order to prevent them from being overwhelmed or inundated.

There are also insights gained regarding the actual programming of sport-fordevelopment projects. This study suggests that with only a limited number of local volunteers facilitating communication and group activities, the set-up and structure of activities need to be flexible. For example, instead of a generalist approach to onpitch and off-pitch training and support, it was recommended that local volunteers should become specialists in one particular activity for the day. Operationally, this requires a change from locals being in charge of one particular group during the day to supervising one particular training station. This adjustment is likely to facilitate a smooth running of activities, as it transfers the responsibility to locals who are able to act with confidence as experts in their particular field.

While Kay (2009) had shown that sport projects can provide people from disadvantaged communities with increased self-confidence derived from increased bodyconfidence, this study shows that people increase their self-confidence through applying and teaching skills and technical sport knowledge. This finding ties in with the community empowerment strategies proposed by different development advocates, who have tried to grow capacities of local talent in areas such as education (Grootaert, Oh \& Swamy, 2002), tourism (Heenan, 1978; Hinch \& Delamere, 1993), sport (Coalter, 2007; Kidd, 2008; Lawson, 2005; Skinner et al., 2008; Vail, 2007), or festivals and event management (Misener \& Mason, 2006; Moscardo, 2007). However, in contrast to previous work this study highlights the importance of interpersonal and inter-community cooperation and dedication in advancing capacities in the context of a divided society.

Finally, in order to benefit from social development on a wider scale, project organisers need to strategically focus on the wider community to grow and leverage individual projects. While Burnett (2006) and Stidder and Haasner (2007) highlighted that a) active participation in sport can be successful in reducing distance between participating people and groups, and b) experts can support local parties with community-building knowledge and educational activities at projects, this research found that a stronger focus around events needs to be designed to make a significant contribution to overall inter-community development efforts (see also Schulenkorf $\&$ Edwards, 2010). Here, the challenge for maximising social outcomes is to transfer the positive atmosphere of the project beyond the borders of the sport arena. To achieve growth and leverage, project organisers and communities could, for example, focus on involving the parents, wider families, friends and finally their communities into project-related support activities or more structured community exchange programs. In other words, a strategic shift towards social leverage requires what Chalip $(2004,2006)$ describes as a focus beyond the planning of direct social impacts to 
achieve lasting social outcomes for communities. Sugden (2010) has shown, this is best achieved by building durable partnerships, first at the level of community, then through durable alliances with a network of other key stakeholders in the surrounding policy communities for sport.

Overall, it becomes obvious that international development agencies, local communities and change agents are becoming increasingly aware of sport and events' social potential. However, we argue that our understanding of this phenomenon still has some distance to travel. For example, despite an increase in practical development projects around the world and the empirical evidence that sport and event projects can be a successful starting point and catalyst for social development (Burnett, 2006; Gasser \& Levinsen, 2004; Stidder \& Haasner, 2007), not many studies have investigated their social, cultural, psychological and educational long-term outcomes. Given earlier discussion, long-term development studies are recommended to assess the sustainability of social outcomes, and the overall contribution of sport and event projects in the inter-community development process.

As an additional step towards evaluating sport-for-development's potential, collaborative research agendas could be developed between different research institutions engaged in sport and event development initiatives. This would help the establishment of more holistic monitoring and investigation methods and instruments. From a qualitative perspective, research could evolve around an examination through case studies of selected project sites in divided societies. From a quantitative perspective, survey-based questionnaires and post-project evaluations could be implemented as an adjunct to qualitative work. Systematic and comparative research of different sport-for-development projects can thus lead to the identification of both strengths and weaknesses, and advantages and disadvantages in strategic planning and management approaches. We argue that the newly gained information should be developed it into a loose sport-for-development framework; a framework which can and should inform other inter-community projects around the world - as long as it is flexible enough to be filled with culturally relevant and meaningful content.

\section{References}

Allen, W. E. D. \& Muratoff, P. (1953). Caucasian Battlefields: History of the Wars on the Turco-Caucasian Border 1821-1921. Cambridge: Cambridge University Press.

Ateek, N. (1989). Justice and Only Justice. Maryknoll, N.Y.: Orbis.

Burnett, C. (2001). Social Impact Assessment and Sport Development: Social Spin-Offs of the Australia-South Africa Junior Sport Programme. International Review for the Sociology of Sport, 36 (1), 41-57.

Burnett, C. (2006). Building Social Capital through an 'Active Community' Club. International Review for the Sociology of Sport, 41 (3-4), 283-294. 
Chalip, L. (2004). Beyond impact: a general model for host community event leverage. In B. Ritchie \& D. Adair (Eds.), Sport tourism: Interrelationships, impacts and issues (pp. 226-252), Clevedon: Channel View.

Chalip, L. (2006). Towards Social Leverage of Sport Events. Journal of Sport and Tourism, 11 (2), 109-127.

Christenson, J. A., Fendley, K. \& Robinson, J. W. (1989). Community Development. In J. A. Christenson \& J. W. Robinson (Eds.), Community Development in Perspective (pp. 3-25), Ames, IA: Iowa State University Press.

Coalter, F. (2007). A Wider Social Role for Sport: Who's Keeping the Score. Abingdon, Oxon: Routledge.

Coalter, F. (2010). The politics of sport-for-development: Limited focus programmes and broad gauge problems? International Review for the Sociology of Sport, 45 (3), 295-314.

Crotty, M. (1998). The Foundations of Social Research. St. Leonards, Sydney: Allen \& Unwin.

Darnell, S. C. (2007). Playing with Race: Right to Play and the Production of Whiteness in 'Development through Sport'. Sport in Society, 10 (4), 560-579.

Denzin, N. K. \& Lincoln, Y. S. (2005). The SAGE handbook of qualitative research (3 ${ }^{\text {rd }}$ ed.). Thousand Oaks: Sage Publications.

Gasser, P. K. \& Levinsen, A. (2004). Breaking Post-War Ice: Open Fun Football Schools in Bosnia and Herzegovina. Sport in Society, 7 (3), 457-472.

Glesne, C. (1999). Meeting Qualitative Inquiry. In C. Glesne \& A. Peshkin (Eds.), Becoming Qualitative Researchers: An Introduction (2 ${ }^{\text {nd }}$ ed., pp. 1-17), New York: Longman.

Green, M. \& Houlihan, B. (2005). Elite Sport Development: Policy Learning and Political Priorities. London; New York: Routledge.

Grootaert, C., Oh, G.-T. \& Swamy, A. (2002). Social capital, education and credit markets: empirical evidence from Burkina Faso. In J. Isham, T. Kelly \& S. Ramaswamy (Eds.), Social Capital and Economic Development (pp. 85-103), Cheltenham, UK: Edgar Elgar Publications.

Gschwend, A. \& Selvaranju, U. (2007). Psycho-social sport programmes to overcome trauma in post-disaster interventions. Biel/Bienne: Swiss Academy for Development (SAD).

Heenan, D. A. (1978). Tourism and the Community: a Drama in Three Acts. Journal of Travel Research, 16 (4), 30-32.

Hinch, T. D. \& Delamere, T. A. (1993). Native Festivals as Tourism Attractions: A Community Challenge. Journal of Applied Recreation Research, 18 (2), 131-142.

Ife, J. W. (1995). Community development: creating community alternatives - vision, analysis and practice. Melbourne: Longman Australia.

Kay, T. (2009). Developing through sport: evidencing sport impacts on young people. Sport in Society, 12 (9), 1177-1191.

Kidd, B. (2008). A new social movement: Sport for development and peace. Sport in Society, 11 (4), 370-380.

Kramer, R. M. \& Specht, H. (1975). Readings in community organization practice (2nd ed.). Englewood Cliffs, N.J.: Prentice-Hall. 
Kunz, V. (2009). Sport as a post-disaster psychosocial intervention in Bam, Iran. Sport in Society, 12 (9), 1147-1157.

Lawson, H. A. (2005). Empowering people, facilitating community development, and contributing to sustainable development: the social work of sport, exercise, and physical education programs. Sport, Education and Society, 10 (1), 135-160.

Levermore, R. \& Beacom, A. (Eds.). (2009). Sport and International Development. Houndmills: Palgrave Macmillan.

Meier, M. \& Saavedra, M. (2009). Esther Phiri and the Moutawakel effect in Zambia: an analysis of the use of female role models in sport-for-development. Sport in Society, 12 (9), 1158-1176.

Midgley, J. (1986). Community Participation, Social Development and the State. New York: Methuen.

Miles, M. \& Huberman, A. (1994). Qualitative data analysis: an expanded sourcebook. California: Sage Publications.

Misener, L. \& Mason, D. S. (2006). Creating community networks: Can sporting events offer meaningful sources of social capital? Managing Leisure, 11 (1), 39-56.

Moscardo, G. (2007). Analyzing the Role of Festivals and Events in Regional Development. Event Management, 11 (1-2), 23-32.

Murphy, P. (1988). Community driven tourism planning. Tourism Management, 9 (2), 96-104.

Myers, M. D. (1997). Qualitative Research in Information Systems. MIS Quarterly, 21 (2), 241-242.

Naparstek, A. J., Dooley, D. \& Smith, R. (1997). Community Building in Public Housing. Washington, DC: U.S. Department of Housing and Urban Development.

Neuman, W. L. (2003). Social research methods: qualitative and quantitative approaches ( $5^{\text {th }}$ ed.). Boston; London: Allyn and Bacon.

Said, E. (2002). The End of the Peace Process. London: Granta.

Schulenkorf, N. (2010a). The Roles and Responsibilities of a Change Agent in Sport Event Development Projects. Sport Management Review, 13 (2), 118-128.

Schulenkorf, N. (2010b). Sport events and ethnic reconciliation: Attempting to create social change between Sinhalese, Tamil and Muslim sportspeople in war-torn Sri Lanka. International Review for the Sociology of Sport, 45 (3), 273-294.

Schulenkorf, N. \& Edwards, D. (2010). The Role of Sport Events in Peace Tourism. In O. Moufakkir \& I. Kelly (Eds.), Tourism, Progress and Peace (pp. 99-117), Oxfordshire, UK: CABI International.

Skinner, J., Zakus, D. \& Cowell, J. (2008). Development through Sport: Building Social Capital in Disadvantaged Communities. Sport Management Review, 11 (3), 253275.

Spaaij, R. (2009). The social impact of sport: diversities, complexities and contexts. Sport in Society, 12 (9), 1109-1117.

Stake, R. (1995). The Art of Case Study Research. California: Sage Publications. 
Stidder, G. \& Haasner, A. (2007). Developing outdoor and adventurous activities for coexistence and reconciliation in Israel: an Anglo-German approach. Journal of Adventure Education and Outdoor Learning, 7 (2), 131-140.

Sugden, J. (2006). Teaching and Playing Sport for Conflict Resolution and Co-Existence in Israel. International Review for the Sociology of Sport, 41 (2), 221-240.

Sugden, J. (2010). Critical left-realism and sport interventions in divided societies. International Review for the Sociology of Sport, 45 (3), 258-272.

Sugden, J. \& Haasner, A. (2010). Sport intervention in divided societies. In W. Tokarski \& K. Petry (Eds.), Handbuch Sportpolitik (pp. 332-342), Schorndorf: HofmannVerlag.

Sugden, J. \& Wallis, J. (2007). Football for Peace? The Challenges of Using Sport for Co-Existence in Israel. Oxford: Meyer \& Meyer Sport.

Uruena, N. (2004). Citizen participation as a means of controlling corruption at the local level in Colombia. M.Sc. Thesis, Oxford University, Oxford.

Vail, S. (2007). Community development and sports participation. Journal of Sport Management, 21 (4), 571-596.

Whitfield, G. (2006). Amity in the Middle East. Brighton: The Alpha Press.

Nico Schulenkorf works as Lecturer in Sport and Event Management at the University of Technology, Sydney (UTS). His research focuses on the social, cultural and psychological utility of sport, and in particular the role of inter-community sport events in contributing to social development between disparate communities. For several years, Nico has been involved in sport-for-development programs in Sri Lanka, Israel and the Pacific Islands. For his long-term contribution to the advancement of social justice on an international level, Nico was awarded the 2008 UTS Vice Chancellor's Human Rights Award. University of Technology, Sydney, School of Leisure, Sport and Tourism, PO Box 222, Lindfield 2070, NSW, Australia

E-mail: nico.schulenkorf@aut.ac.nz

John Sugden is Professor of the Sociology of Sport at the University of Brighton's Chelsea School where he has been since 1996. He has researched and written widely around topics concerned with the politics and sociology of sport. Professor Sugden is also well known for his work on sport in divided societies, his studies of the world governing body for football, FIFA, and for his investigative research into football's underground economy. Professor Sugden is the Director of the University of Brighton's flagship international community relations project in Israel, 'Football for Peace'.

University of Brighton, Chelsea School of Sport, Hillbrow, Denton Road, Eastbourne, East Sussex, BN20 7SR, United Kingdom

E-mail: J.Sugden@brighton.ac.uk 